\title{
Effects of Ticagrelor and Clopidogrel on Coronary Microcirculation in Patients with Acute Myocardial Infarction
}

\author{
Marco Antonio Scanavini-Filho - Otavio Berwanger - Wilson Matthias · Miguel O. Aguiar · Hsu P. Chiang • \\ Luciene Azevedo · Luciano M. Baracioli · Felipe G. Lima · Remo H. M. Furtado • Talia F. Dalcoquio • \\ Fernando R. Menezes · Aline G. Ferrari · Fabio de Luca · Robert P. Giugliano · Shaun Goodman • \\ José C. Nicolau
}

Received: November 3, 2021 / Accepted: January 25, 2022 / Published online: February 26, 2022

(C) The Author(s) 2022

\begin{abstract}
Introduction: Clopidogrel has been demonstrated to be effective in improving coronary microcirculation (CM) among patients with STelevation myocardial infarction (STEMI) treated
\end{abstract}

Supplementary Information The online version contains supplementary material available at https:// doi.org/10.1007/s12325-022-02061-0.

M. A. Scanavini-Filho · W. Matthias .

M. O. Aguiar · H. P. Chiang · L. Azevedo .

L. M. Baracioli · F. G. Lima - R. H. M. Furtado .

T. F. Dalcoquio · F. R. Menezes - A. G. Ferrari ·

F. de Luca · J. C. Nicolau

Instituto do Coracao do Hospital das Clinicas da

FMUSP, 44 Dr Enéas Carvalho de Aguiar Ave, São

Paulo, SP 05403-000, Brazil

M. A. Scanavini-Filho

e-mail: marco_scanavini@hotmail.com

W. Matthias

e-mail: wmathias@incor.usp.br

M. O. Aguiar

e-mail: cardiodermamf@hotmail.com

H. P. Chiang

e-mail: hsu.pochiang@gmail.com

L. Azevedo

e-mail: luciene.azevedo@usp.br

L. M. Baracioli

e-mail: lumobaracioli@gmail.com with fibrinolytics. Ticagrelor is a more potent adenosine diphosphate (ADP) receptor blocker proven to be superior to clopidogrel among patients with acute coronary syndromes. The present study aimed to compare the effects of ticagrelor and clopidogrel on $\mathrm{CM}$ in patients with STEMI treated with fibrinolytics.

Methods: The present study prospectively included 48 patients participating in the TREAT trial, which randomly assigned patients with

\section{F. G. Lima}

e-mail: felipeglima@yahoo.com.br

R. H. M. Furtado

e-mail: rhmfurtado@gmail.com

T. F. Dalcoquio

e-mail: taliadalcoquio@gmail.com

F. R. Menezes

e-mail: fernandormenezes@gmail.com

A. G. Ferrari

e-mail: alinegferrari@gmail.com

F. de Luca

e-mail: deluca.cardio@gmail.com

R. P. Giugliano

Brigham and Women's Hospital, Harvard Medical School, 350 Longwood Ave, Boston, MA 02215, USA e-mail: rgiugliano@bwh.harvard.edu

S. Goodman

St. Michael's Hospital, University of Toronto, 36 Queen St E, Toronto, ON M5B 1W8, Canada

e-mail: goodmans@chrc.net 
STEMI undergoing fibrinolysis to ticagrelor versus clopidogrel. The primary endpoint of this study was the evaluation of the CM using the global myocardial perfusion score index (global MPSI) obtained by myocardial contrast echocardiography (MCE). Platelet aggregation to ADP was evaluated by Multiplate ${ }^{\circledR}$ and expressed as area under the curve (AUC).

Results: The global MPSI demonstrated no differences between the groups [mean 1.4 (1.2-1.5) in the ticagrelor group and $1.2(1.2-1.5)$ in the clopidogrel group $(p=0.41)]$. Platelet aggregability was lower in the ticagrelor group $(18.1 \pm 9.7$ AUC), compared to the clopidogrel group $(26.1 \pm 12.5$ AUC, $p=0.01)$.

Conclusion: We found no improvement in coronary microcirculation with ticagrelor compared to clopidogrel among patients with STEMI treated with fibrinolytics, despite the fact that platelet aggregation to ADP was lower with ticagrelor.

Clinical Trials Registration: NCT03104062.

Keywords: Coronary microcirculation; Ticagrelor; Clopidogrel; Myocardial contrast echocardiography; Myocardial perfusion score index

\section{Key Summary Points}

Clopidogrel improves microcirculation in ST-elevation myocardial infarction (STEMI) treated with fibrinolytics, when compared with placebo.

In acute coronary syndrome, ticagrelor is superior to clopidogrel in terms of hard endpoint incidences.

We analyzed the effect of ticagrelor or clopidogrel on coronary microcirculation in patients presenting with STEMI.

\section{O. Berwanger}

Hospital Israelita Albert Einstein, 627 Albert Einstein Ave, São Paulo, SP 05652-900, Brazil e-mail: otavioberwanger@gmail.com

J. C. Nicolau ( $\square)$

Rua Mato Grosso 306, CJ 713, São Paulo, SP 01239040, Brazil

e-mail: jose.nicolau@incor.usp.br
Despite lower platelet reactivity with ticagrelor, in comparison with clopidogrel, there is no difference between the effect of the drugs on coronary microcirculation in patients with STEMI treated with fibrinolytics.

\section{INTRODUCTION}

Patients with ST-elevation myocardial infarction (STEMI) are exposed to high residual risk of cardiovascular (CV) adverse events despite timely coronary reperfusion. It is known from patients diagnosed with STEMI undergoing coronary reperfusion therapy who have TIMI 3 flow grade that approximately $40 \%$ still have some degree of impaired blood flow in the coronary microcirculation (CM), which leads to worse left ventricular remodeling (LVR) with a consequent increase in mortality, compared to those with normal CM flow [1, 2].

In a sub-analysis from the CLARITY-TIMI 28 study, clopidogrel improved microcirculation flow parameters assessed by coronary angiography when compared to placebo. In addition, a significant improvement in $\mathrm{CM}$ (relative risk reduction, RRR 21\%; $p=0.008$ ) was demonstrated with clopidogrel [3].

Ticagrelor is a more potent ADP receptor blocker that reduced major adverse CV events compared to clopidogrel among patients with acute coronary syndrome (ACS) in the PLATO study [4]. However, patients with STEMI treated with fibrinolytics were not included in the this study. The TREAT trial tested the safety of ticagrelor compared to clopidogrel in patients with STEMI treated with fibrinolytics, and demonstrated that ticagrelor was non-inferior to clopidogrel regarding the main endpoint of TIMI major bleeding [5-7].

The superiority of ticagrelor over clopidogrel in the PLATO Trial, including a significant decrease in cardiovascular mortality, is not fully understood. Considering the superior antiplatelet effect of ticagrelor, and the fact that it may increase circulating adenosine levels, 
which acts favorably in $\mathrm{CM}[8,9]$, it could be speculated that a more efficient action of ticagrelor on CM could explain, at least partially, the results obtained.

In order to test this hypothesis, the present study aimed to compare the influence of ticagrelor and clopidogrel on CM in patients with STEMI treated with fibrinolytics.

\section{METHODS}

\section{Study Design}

The present study prospectively included 48 patients participating in the TREAT trial, which analyzed 3799 patients with STEMI treated with fibrinolytics and randomized to open-label ticagrelor versus clopidogrel. Details of the TREAT protocol were previously published, as well as the primary and secondary results [5-7]. Briefly, the main inclusion criteria were patients diagnosed with STEMI within $24 \mathrm{~h}$ after the onset of symptoms and treated with fibrinolytics as the primary strategy of reperfusion.

Patients in the present substudy were included between September 2016 and September 2017, admitted consecutively to the Coronary Care Unit (CCU) of the Instituto do Coração (InCor)/HCFMUSP as soon as possible after its randomization in the TREAT trial. Patients were randomized and received the initial medication (including fibrinolytics and ticagrelor or clopidogrel) in two referring sites, being transferred to InCor/HCFMUSP on a routine basis to undergo coronary angiography and percutaneous coronary intervention (PCI) whenever indicated. Randomization was performed using a central concealed, web-based, central, automated, randomization system. Those who at the end of the angiography had residual obstruction in the culprit artery of less than 50\% with TIMI 3 flow were eligible for the present study, whether they have undergone PCI or not. Key exclusion criteria were mainly previous infarction at the same infarct area location as the current one, among other criteria of the TREAT trial [5-7] (see supplementary material).

Patients who met the eligibility criteria and agreed to participate in the present study by signing the informed consent form were then submitted to evaluation of CM by myocardial contrast echocardiography (MCE; see supplementary material for more details). MCEs were performed by two specially trained different echocardiographers following a dedicated protocol, and analyzed by a single professional with extensive experience in the area (WM), all of whom were blinded to randomized (ticagrelor vs. clopidogrel) treatment assignment. In addition, blood samples for platelet aggregability assessment, among others, were collected concomitantly with MCE test. Staff who measured platelet aggregability and other laboratory tests were also unaware of the study drug assignments.

\section{Study Outcomes}

The primary outcome of the study was to compare the influence of ticagrelor versus clopidogrel on $\mathrm{CM}$, considering the global myocardial perfusion score index (global MPSI) obtained by MCE performed $6 \pm 3$ days after the onset of symptoms. Secondary outcomes were to compare ticagrelor with clopidogrel considering other echocardiographic parameters: (1) regional myocardial perfusion score index (regional MPSI); (2) infarction area analysis (IAA); (3) global wall motion score index (global WMSI); (4) regional wall motion score index (regional WMSI); (5) presence or not of coronary artery no-reflow. Additionally, platelet aggregability for ticagrelor and clopidogrel groups was obtained by Multiplate analysis [10].

\section{Myocardial Contrast Echocardiography}

For the analysis of MPSI by MCE, the left ventricle was divided into 17 segments. Each segment was graded with a perfusion score (PS), where PS $=1$ represents normal opacification, $\mathrm{PS}=2$ represents reduced opacification, and PS $=3$ represents absence of opacification. In the case of visual limitations of a given segment, $\mathrm{PS}=0$. The global MPSI was then obtained by adding the PS of each segment divided by the number of total segments $(n=17)$. As in the perfusion assessment, to assess contractility, 
each segment was graded with a motion score (MS), where MS = 1 represents normal contractility, MS $=2$ represents reduced contractility, and MS $=3$ represents absence of contractility. In the case of visual limitations of a particular segment, MS $=0$. The global WMSI was then obtained by adding the MS of each segment divided by the number of total segments $(n=17)$.

\section{Sample Size Calculation}

The main hypothesis was tested considering a difference of $20 \%$ in favor of ticagrelor in the global MPSI, based on the same difference found in the CLARITY-TIMI 28 study in favor of clopidogrel over placebo on CM (RRR 21\%; $p=0.008)$. Considering the mean global MPSI of $1.4 \pm 0.2$, obtained with a methodology similar to that used in the present study in patients diagnosed with STEMI undergoing fibrinolytic treatment previously by our group [11], a sample size calculation revealed that 40 patients (20 per group) would yield $90 \%$ statistical power with an alpha $<0.01$. Considering possible technical difficulties, a final sample of 48 patients ( 24 patients per group) was planned.

\section{Statistical Analysis}

The results are presented as absolute numbers and percentages (categorical variables), or means $\pm \mathrm{SD}$ (continuous variables with Gaussian distribution), or medians with 25 th-75th percentiles (continuous variables with nonGaussian distribution). Kolmogorov-Smirnov test was used for normality assessment. Categorical variables were compared using the chisquare test or Fisher's exact test as appropriate. Continuous variables were compared using the Student's $t$ test (Gaussian distribution) or Wilcoxon rank sum test (non-Gaussian distribution). To assess the correlations of two variables, linear regression models were used.

No adjustment for multiplicity was performed. Since the proportion of missing data for the primary outcome was less than $1 \%$, no imputation model was developed. All tests are two-tailed and a $p$ value less than 0.05 is considered as statistically significant. The software used in all statistical analysis was Stata/SE $15.1{ }^{\circledR}$.

\section{Ethical Issues}

This protocol is in accordance with the recommendations contained in the Declaration of Helsinki and was approved, together with the free and informed consent form by the Scientific Committee of InCor/HCFMUSP and by the Research Ethics Committee of HCFMUSP, before the beginning of the study. The study was registered at ClinicalTrials.gov (NCT03104062).

\section{RESULTS}

\section{Population Characteristics}

The characteristics of the study population, upon arrival at InCor/HCFMUSP, are detailed in Table 1. As expected, the ticagrelor and clopidogrel groups were well balanced, with no significant differences between them in relation to the analyzed parameters. The median age of the population was 56.5 years, and $60.4 \%$ were men. The median times between symptom onset and fibrinolysis were 200 (150-290) and 160 (95-207.5) mins in ticagrelor and clopidogrel groups, respectively, and the median times between symptom onset and CM evaluation by MCE were 5.1 (4-6.2) and 4.5 (3-5.6) days, respectively.

The use of clopidogrel prior to randomization in the TREAT study was the same in both groups $(54.1 \%)$.

The frequencies of culprit vessels for STEMI were similar in both groups. There were no statistically significant differences between the two groups regarding the medications used during hospitalization, with the exception of ranitidine $(79.1 \%$ in the ticagrelor group versus $100 \%$ in the clopidogrel group, $p=0.018$ ). 
Table 1 Characteristics of the population

$$
\begin{array}{lll}
\text { Total }(n=48) & \begin{array}{l}
\text { Ticagrelor } \\
(n=24)
\end{array} & \begin{array}{l}
\text { Clopidogrel } \\
(n=24)
\end{array}
\end{array}
$$

Evaluation upon arrival at InCor

Age, years [median (p25-p75)]

Male sex, $n(\%)$

Body mass index, $\mathrm{kg} / \mathrm{m}^{2}$ [mean $\left.( \pm \mathrm{SD})\right]$

Hypertension, $n(\%)$

Type II diabetes, $n$ (\%)

Dyslipidemia, $n$ (\%)

Smoking, $n$ (\%)

Family history for CAD, $n$ (\%)

Chronic kidney disease $(\mathrm{ClCr}<60 \mathrm{ml} / \mathrm{min}), n$ (\%)

Previous myocardial infarction

Time from symptom onset to fibrinolysis, in mins [median (p25-p75)]

Time from symptom onset to arrival at CCU, in days [median $1.6(0.7-2.7)$ (p25-p75)]

Time from symptom onset to PCI, in days [median (p25-p75)]

Time from symptom onset to MCE, in days [median (p25-p75)]

Anterior MI, $n$ (\%)

Killip 1, $n(\%)$

Killip 2, $n$ (\%)

TIMI risk score-low, $n$ (\%)

TIMI risk score-moderate, $n$ (\%)

TIMI risk score-high, $n$ (\%)

Use of clopidogrel before randomization in TREAT trial, $n(\%)$

Variables obtained during hospitalization at InCor

Hemodynamic data

Culprit coronary artery

Anterior descending artery, $n$ (\%)

Circumflex artery, $n(\%)$

Right coronary artery, $n$ (\%)

$\begin{array}{lll}56.5(51.0-64.5) & 61(54.5-67.0) & 55(48.5-63.5) \\ 29(60.4 \%) & 14(58.3 \%) & 10(41.6 \%) \\ 26.8( \pm 4.6) & 26.9( \pm 4.5) & 26.8( \pm 4.7) \\ 24(50 \%) & 12(50 \%) & 12(50 \%) \\ 11(22.9 \%) & 6(25 \%) & 5(20.8 \%) \\ 16(33.3 \%) & 10(41.6 \%) & 6(25 \%) \\ 38(79.1 \%) & 19(79.1 \%) & 19(79.1 \%) \\ 9(18.7 \%) & 6(25 \%) & 3(12.5 \%) \\ 2(4.1 \%) & 2(8.3 \%) & 0 \\ 0 & 0 & 0 \\ 180(120-255) & 200(150-290) & 160(95-207.5)\end{array}$

$1.5(0.5-2.8) \quad 1.6(0.8-2.7)$

$2.4(1.4-3.6) \quad 2.5(1.2-4.0) \quad 2.3(1.7-3.5)$

$4.7(3.6-6.2) \quad 5.1(4.0-6.2) \quad 4.5(3.0-5.6)$

$22(45.8 \%) \quad 8(33.3 \%) \quad 14(58.3 \%)$

$45(93.7 \%) \quad 21(87.5 \%) \quad 24(100 \%)$

$3(6.2 \%) \quad 3(12.5 \%) \quad 0$

$31(64.5 \%) \quad 15(62.5 \%) \quad 16(66.6 \%)$

$16(33.3 \%) \quad 8(33.3 \%) \quad 8(33.3 \%)$

$1(2 \%) \quad 1(4.1 \%) \quad 0$

$26(54.1 \%) \quad 13(54.1 \%) \quad 13(54.1 \%)$

$\begin{array}{lll}22(45.8 \%) & 9(37.5 \%) & 13(54.1 \%) \\ 6(12.5 \%) & 4(16.6 \%) & 2(8.3 \%) \\ 20(41.6 \%) & 11(45.8 \%) & 9(37.5 \%)\end{array}$

$\underline{\Lambda}$ Adis 
Table 1 continued

\begin{tabular}{|c|c|c|c|}
\hline & Total $(n=48)$ & $\begin{array}{l}\text { Ticagrelor } \\
(n=24)\end{array}$ & $\begin{array}{l}\text { Clopidogrel } \\
(n=24)\end{array}$ \\
\hline Rescue angioplasty, $n$ (\%) & $5(10.4 \%)$ & $2(8.3 \%)$ & $3(12.5 \%)$ \\
\hline Percutaneous coronary intervention, $n(\%)$ & $41(85.4 \%)$ & $22(91.6 \%)$ & $19(79.1 \%)$ \\
\hline Exclusive clinical treatment & $7(14.5 \%)$ & $2(8.3 \%)$ & $5(20.8 \%)$ \\
\hline Residual lesion in non-culprit arteries, $n(\%)$ & $20(41.6 \%)$ & $13(54.1 \%)$ & $7(29.1 \%)$ \\
\hline \multicolumn{4}{|l|}{ Medications used during hospitalization } \\
\hline Acetylsalicylic acid, $n(\%)$ & $48(100 \%)$ & $24(100 \%)$ & $24(100 \%)$ \\
\hline Enoxaparin, $n(\%)$ & $48(100 \%)$ & $24(100 \%)$ & $24(100 \%)$ \\
\hline Statin, $n(\%)$ & $48(100 \%)$ & $24(100 \%)$ & $24(100 \%)$ \\
\hline Angiotensin-converting enzyme inhibitor, $n(\%)$ & $47(97.9 \%)$ & $24(100 \%)$ & $23(95.8 \%)$ \\
\hline Beta-blocker, $n(\%)$ & $44(91.6 \%)$ & $22(91.6 \%)$ & $22(91.6 \%)$ \\
\hline Morphine, $n(\%)$ & $13(27 \%)$ & $6(25 \%)$ & $7(29.1 \%)$ \\
\hline Proton pump inhibitor, $n(\%)$ & $10(20.8 \%)$ & $6(25 \%)$ & $4(16.6 \%)$ \\
\hline Ranitidine, $n(\%)^{\dagger}$ & $43(89.5 \%)^{\dagger}$ & $19(79.1 \%)^{\dagger}$ & $24(100 \%)^{\dagger}$ \\
\hline \multicolumn{4}{|l|}{ Laboratory data } \\
\hline Leukocytes, per $\mathrm{mm}^{3}[$ mean $( \pm \mathrm{SD})]$ & $\begin{array}{l}10,525 \\
\quad( \pm 2932)\end{array}$ & $\begin{array}{l}10,519 \\
\quad( \pm 2519)\end{array}$ & $10,530( \pm 3351)$ \\
\hline Platelet count, $\mu \mathrm{L}[$ mean $( \pm \mathrm{SD})]$ & $\begin{array}{l}223,208 \\
\quad( \pm 61,633)\end{array}$ & $\begin{array}{l}218,500 \\
( \pm 58,410)\end{array}$ & $\begin{array}{l}227,916 \\
\quad( \pm 65,608)\end{array}$ \\
\hline Average platelet volume, fL [median (p25-p75)] & $11(10.3-11.6)$ & $11.1(10.4-11.7)$ & $10.9(10.3-11.6)$ \\
\hline Creatinine, mg/dL [median (p25-p75)] & $0.8(0.7-1.0)$ & $0.8(0.7-1.0)$ & $0.8(0.7-1.0)$ \\
\hline Glycated hemoglobin,\% [median (p25-p75)] & $5.8(5.4-6.0)$ & $5.8(5.4-6.1)$ & $5.7(5.5-5.9)$ \\
\hline Blood glucose, mg/dL [median (p25-p75)] & $105(97-122)$ & $118(100-128)$ & $102(94-110)$ \\
\hline C-reactive protein, mg/L $[$ median $(\mathrm{p} 25-\mathrm{p} 75)]$ & $18(5-38.1)$ & $18.5(4.6-46.3)$ & $17.1(5.3-31.9)$ \\
\hline Interleukin-6 [median (p25-p75)] & $4.4(1.7-7.2)$ & $4.2(2.2-8.1)$ & $4.4(1.5-7.2)$ \\
\hline Natriuretic peptide type B, pg/mL [median (p25-p75)] & $128(88-215)$ & $170(88-286)$ & $118(88-180)$ \\
\hline Troponin, ng/mL [median (p25-p75)] & $29.6(10.5-50)$ & $38.8(14.4-50)$ & $24.0(8.5-46.9)$ \\
\hline CKMB-mass, ng/mL [median (p25-p75)] & $17.4(4.4-58.9)$ & $18.6(3.3-108.6)$ & $15.6(5.9-41.9)$ \\
\hline Total cholesterol, mg/dL $[$ mean $( \pm S D)]$ & $198( \pm 51)$ & $207( \pm 55)$ & $189( \pm 46)$ \\
\hline LDL-cholesterol, mg/dL $[$ mean $( \pm \mathrm{SD})]$ & $125( \pm 42)$ & $131( \pm 41)$ & $119( \pm 42)$ \\
\hline HDL-cholesterol, mg/dL [mean $( \pm S D)]$ & $41( \pm 10)$ & $42( \pm 12)$ & $41( \pm 8)$ \\
\hline
\end{tabular}


Table 1 continued

\begin{tabular}{llll}
\hline & Total $(\boldsymbol{n}=48)$ & $\begin{array}{l}\text { Ticagrelor } \\
(\boldsymbol{n}=\mathbf{2 4})\end{array}$ & $\begin{array}{l}\text { Clopidogrel } \\
(\boldsymbol{n}=\mathbf{2 4})\end{array}$ \\
\hline Triglycerides, mg/dL [median $(\mathrm{p} 25-\mathrm{p} 75)]$ & $133(90-185)$ & $132(92-185)$ & $141(90-191)$ \\
\hline
\end{tabular}

$C C U$ coronary care unit, $P C I$ percutaneous coronary intervention, $M C E$ myocardial contrast echocardiography ${ }^{\dagger} p=0.018$. There were no statistically significant differences between the other groups

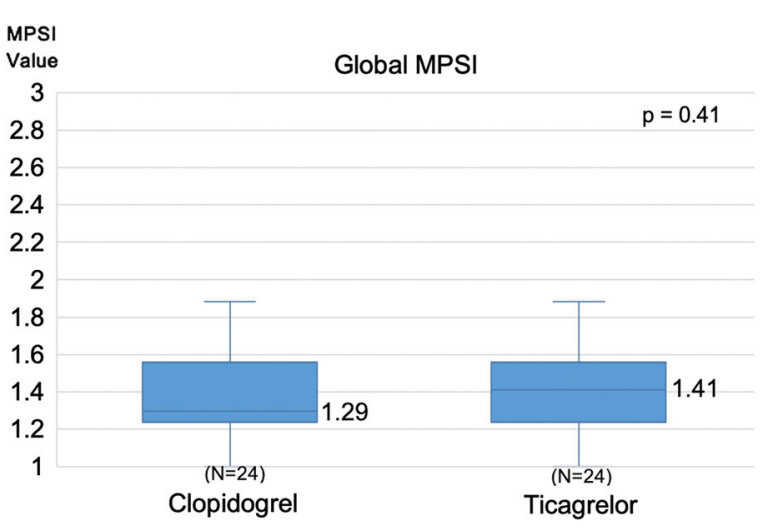

Fig. 1 Median of global MPSI (main objective of the study). Global MPSI, global myocardial perfusion score index (values range from 1 to 3 , with 1 being adequate myocardial perfusion and 3 absence of myocardial perfusion). The values are presented as median ( $225-\mathrm{p} 75)$

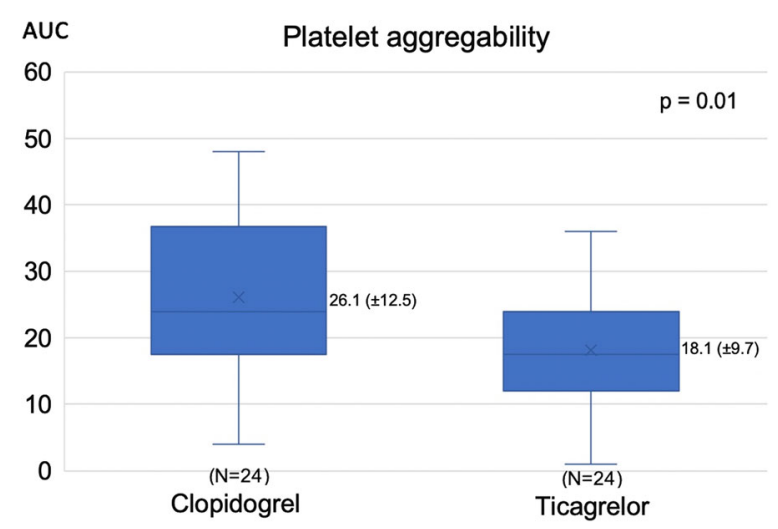

Fig. 2 Mean platelet aggregability assessed by Multiplate. Multiplate, in AUC. The values are presented as average ( \pm standard deviation)

\section{Primary Objective}

Assessment of CM obtained by global MPSI are depicted in Fig. 1, with no significant differences being observed between the two groups: 1.41 (1.23-1.52) in the ticagrelor group and $1.29(1.23-1.52)$ in the clopidogrel group $(p=0.417)$.

As seen in Fig. 2, platelet aggregability to ADP as assessed by Multiplate ${ }^{\circledR}$ was lower in the ticagrelor group $(18.1 \pm 9.7$ AUC) than in the clopidogrel group $(26.1 \pm 12.5$ AUC, $p=0.017)$.

\section{Pre-specified Secondary Outcomes: Analysis of Coronary Microcirculation and Left Ventricular Contractility by Echocardiography}

The results of the secondary outcomes of the study in relation to $\mathrm{CM}$ and contractility by echocardiography are detailed in Table 2 . When evaluation of the CM was restricted to the segments related to the culprit artery, obtained by the regional MPSI, there were no differences between the groups [ticagrelor 1.7 (1.5-1.9) vs. clopidogrel $1.5 \quad(1.4-1.7), \quad$ respectively, $p=0.243]$. Similarly, the assessment of left ventricular contractility obtained by the global WMSI was not different between the groups [(1.6 (1.3-2.0) and $1.4(1.2-1.6)]$, respectively, $p=0.124]$.

In the evaluation of the IAA, "red" did not show any significant differences between the groups [(22.9\% (18.7-31.4) of the left ventricular area in the ticagrelor group and $21.0 \%$ (15-24.2) in the clopidogrel group, $p=0.152)$ ]. The same pattern was obtained for "yellow", which showed no significant differences between the groups [(10.1\% (5.8-15.6) of the left ventricular area in the ticagrelor group, $15.6 \%(10.8-17.9)$ in the clopidogrel group, $p=0.059)]$. 
Table 2 Results of pre-specified secondary analyzes: microcirculation and contractility on echocardiography

\begin{tabular}{lccc}
\hline & Ticagrelor $(\boldsymbol{n}=\mathbf{2 4})$ & Clopidogrel $(\boldsymbol{n}=\mathbf{2 4})$ & $\boldsymbol{p}$ value \\
\hline Regional MPSI [median (p25-p75)] & $1.7(1.5-1.9)$ & $1.5(1.4-1.7)$ & 0.24 \\
Global WMSI [median (p25-p75)] & $1.6(1.3-2.0)$ & $1.4(1.2-1.6)$ & 0.12 \\
Regional WMSI [median (p25-p75)] & $2.1(1.6-2.5)$ & $1.7(1.3-2.2)$ & 0.06 \\
Infarcted area analysis (red), \% [median (p25-p75)] & $22.9(18.7-31.4)$ & $21.0(15-24.2)$ & 0.15 \\
Infarcted area analysis (yellow), \% [median (p25-p75)] & $10.1(5.8-15.6)$ & $15.6(10.8-17.9)$ & 0.05 \\
Presence of "no reflow", $n$ (\%) & $10(41.6 \%)$ & $7(29.1 \%)$ & 0.36 \\
\hline
\end{tabular}

Values range from 1 to 3,1 being adequate myocardial perfusion/contractility and 3 absence of myocardial perfusion/contractility

Red means absence of microcirculation flow; yellow means decrease of microcirculation flow; no reflow was defined as absence of microcirculation flow in two or more segments of the left ventricle

Regional MPSI regional myocardial perfusion score index, Global WMSI global wall motion score index, Regional WMSI regional wall motion score index

\section{DISCUSSION}

In our study, which compared the impact of ticagrelor versus clopidogrel on coronary microcirculation evaluated by MCE in patients with STEMI treated with fibrinolytics, we observed similar results between the two groups. Other findings from the present study reinforced this neutral result, such as the assessment of $\mathrm{CM}$ in the segments of the left ventricle related to the culprit artery, or the assessment of CM obtained through the analysis of the infarct area.

In a recent study, Park et al. also compared the effect of ticagrelor and clopidogrel on CM in patients with different forms of ACS undergoing PCI, and the results obtained in the initial phase were in line with our present study, with a similar effect of both drugs on CM. The CM analysis was performed invasively (IMR, index of microcirculatory resistance), immediately after the end of the stent implantation. On the other hand, this study also evaluated $\mathrm{CM}$ at 6 months (main study objective) from the onset of symptoms, and in this late evaluation the effect of ticagrelor on CM was superior to that of clopidogrel $(p<0.01)$. However, it is important to note that there are several methodological differences between both studies. In this sense, different from our study, Park et al. evaluated
$\mathrm{CM}$ in patients undergoing PCI and not fibrinolytics, in different types of ACS (only 30\% of patients in each group diagnosed with STEMI). Additionally, in our study, patients with previous infarction on the same wall as the current infarction were excluded, as opposed to the study by Park et al. More importantly, the main objective in the Park et al. study was to analyze the microcirculation in the two groups after 6 months of antiplatelet treatment; $\mathrm{CM}$ was analyzed only in the acute phase in our study, and our findings were similar to those of Park et al.'s during a similar early time window postMI [12].

It should be noted that $\mathrm{CM}$ has an important role in left ventricular contractility in patients with STEMI. Patients with some degree of CM impairment have worse contractility and left ventricular remodeling, consequently with higher mortality $[1,2]$. However, with regard to contractility of the left ventricular segments, our study also did not demonstrate a difference between the two $\mathrm{P}_{2} \mathrm{Y}_{12}$ receptor inhibitor treatment groups, both in the global assessment and in the assessment of only those segments related to the infarct-related artery. 


\section{Population Characteristics}

The TREAT trial predominantly included patients with low-risk STEMI, which mirrored the population of our present study. Regarding age, the TREAT study excluded patients over 75 years old; the median age of 56 years in our substudy was younger than that described in previous studies of patients with STEMI. In addition, the prevalence of diabetes at baseline (22.9\%) was lower than that described in other STEMI cohorts [13-15].

\section{Platelet Aggregability and Fibrinolysis}

As demonstrated in previous studies analyzing other populations [16, 17], the present study also found lower platelet aggregability with ticagrelor, compared to clopidogrel, in patients with STEMI treated with fibrinolytics.

In patients with STEMI treated by primary PCI, ticagrelor is superior to clopidogrel, reducing the relative risk of $\mathrm{CV}$ death, (re)infarction, and stroke by $16 \%(p<0.001)$ [18]. In the TREAT trial, among patients with STEMI undergoing reperfusion with fibrinolytics, there was no evidence of superiority of ticagrelor over clopidogrel regarding clinical outcomes. However, the study was not powered for ischemic endpoints, and point estimates for MACE were consistent with results from the PLATO trial favoring ticagrelor over clopidogrel [5]. Fibrinolytics belong to a class of drugs that promotes fibrinolysis and the consequent dissolution of the thrombus. This effect is based on the transformation of plasminogen into plasmin, a potent proteolytic enzyme $[19,20]$. Its effect on platelets has been the subject of some publications. Diego et al. found a progressive increase in platelet aggregation in the first $24 \mathrm{~h}$ after fibrinolytic treatment $(p=0.001)$ in a study with 41 patients with STEMI undergoing fibrinolytic treatment and on dual antiplatelet therapy with ASA and clopidogrel [21].

To the best of our knowledge, our study represents the first randomized trial to compare the effects ticagrelor and clopidogrel on platelet aggregability in patients with STEMI undergoing fibrinolytic treatment. In our study, platelet aggregation with ticagrelor was lower than with clopidogrel, suggesting a possible effect in this platelet hyperactivation induced by the fibrinolytics. However, this effect did not translate into any sign of improvement in CM.

\section{Study Limitations}

Our study has limitation that merit consideration. Firstly, the patients from our study were included in the TREAT trial, which had an open-label design. In order to minimize this limitation, the echocardiography operator was blinded to the randomized group, and the echocardiography analyses were developed also in a blinded way by a single observer. Secondly, the time of exposure to the effect of ticagrelor [5.1 (4-6.2) days] may have been insufficient for the drug to have beneficial and direct effects on $\mathrm{CM}$. Third, the use of fibrinolytics could have affected the microcirculation and influenced the results obtained. However, it is important to note that in the CLARITY-TIMI28 study, which showed superiority of clopidogrel over placebo (RRR 21\%; $p=0.008$ ), the analyses of microcirculation were based on the coronary angiography done 3.5 days after the fibrinolytic, on average [3]. Finally, we used only Multiplate ADP in order to analyze platelet reactivity; ASPI or TRAP tests could add information regarding the issue, but it is important to note that we were comparing two anti-ADP drugs (clopidogrel and ticagrelor); this is the reason why we choose only this path to be analyzed.

\section{CONCLUSION}

We found no improvement in coronary microcirculation with ticagrelor compared to clopidogrel among patients with STEMI treated with fibrinolytics, despite the fact that platelet aggregation to ADP was lower with ticagrelor.

\section{ACKNOWLEDGEMENTS}

We thank the TREAT trial investigators, as well as the participants of the study. 
Funding. This study had no specific funding. The Sonovue kits to perform MCE and Multiplate kits were provided by the TREAT Study coordination. No Rapid Service Fee was received by the journal for the publication of this article.

Authorship. All named authors meet the International Committee of Medical Journal Editors (ICMJE) criteria for authorship for this article, take responsibility for the integrity of the work as a whole, and have given their approval for this version to be published.

Author Contributions. J. C. Nicolau and M. A. Scanavini Filho were responsible for the conception and design of the study; J. Nicolau, R. H. M. Furtado, and T. F. Dalçóquio wrote the draft manuscript; M. A. Scanavini Filho was responsible for the acquisition of data; $M$. O. Aguiar and H. P. Chiang were responsible for the acquisition of echocardiography images. W. Matthias was responsible for analyzing all global MPSI. O. Berwanger, L. Azevedo, L. M. Baracioli, F.G. Lima, F. R. Menezes, A. G. Ferrari, F. de Luca, R. P. Giugliano, and S. Goodman contributed to the interpretation of the data and critically revised the draft manuscript; all authors gave final approval to the present manuscript.

Disclosures. Remo H. de M. Furtado reports research grants and personal fees from AstraZeneca, Bayer, and Servier; and research grants from Pfizer, EMS, Aché, Brazilian Ministry of Health, and University Health Network. Robert P. Giugliano reports grant support to his clinical trials from Amgen, Daiichi Sankyo, and Anthos Therapeutics, and honoraria for CME programs or consulting from Amgen, Daiichi Sankyo and Merck, consulting honoraria from Amarin, American College of Cardiology, Amgen, AstraZeneca, Boehringer Ingelheim, Bristol Myers Squibb, CryoLife, CVS Caremark, Dr. Reddy's Laboratories, Daiichi Sankyo, Eli Lilly, Esperion, Gilead, GlaxoSmithKline, Janssen, Lexicon, Merck, Pfizer, St. Lukes, SAJA Pharmaceuticals, Samsung and Servier. Shaun G. Goodman reports research grant support (e.g., steering committee or data and safety monitoring committee) and/or speaker/consulting honoraria (e.g., advisory boards) from Amgen, AstraZeneca, Bayer, Boehringer Ingelheim, Bristol Myers Squibb, CSL Behring, Daiichi-Sankyo/American Regent, Eli Lilly, Esperion, Ferring Pharmaceuticals, GlaxoSmithKline, HLS Therapeutics, Janssen/ Johnson \& Johnson, Merck, Novartis, Novo Nordisk A/C, Pfizer, Regeneron, Sanofi, Servier; and salary support/honoraria from the Heart and Stroke Foundation of Ontario/University of Toronto (Polo) Chair, Canadian Heart Research Centre and MD Primer, Canadian VIGOUR Centre, Duke Clinical Research Institute, New York University Clinical Coordinating Centre, and PERFUSE Research Institute. Otavio Berwanger reported receiving grants from AstraZeneca, Amgen, Servier, Bristol Myers Squibb, Bayer, Novartis, Pfizer, and Boehringer Ingelheim. José C. Nicolau reports personal fees from AMGEN, grants from AstraZeneca, grants and personal fees from Bayer, grants from Esperion, grants from CLS Behring, personal fees from Daiichi-Sankyo, grants from Dalcor, grants from Janssen, grants and personal fees from Novartis, grants from NovoNordisk, grants and personal fees from Sanofi, personal fees from Servier, grants from Vifor, outside the submitted work; Marco A. Scanavini Filho, Wilson Matthias, Miguel O. Aguiar, Hsu P. Chiang, Luciene Azevedo, Luciano M. Baracioli, Felipe G. Lima, Talia F. Dalçoquio, Fernando R. Menezes, Aline G. Ferrari, and Fabio de Luca have nothing to disclose.

Prior Presentation. Part of the results was presented as an abstract at the 2019 American College of Cardiology Congress as a poster.

Compliance with Ethics Guidelines. This study was approved by the Institutional Review Board of the Ethics Committee (Comissão de Ética para Análise de Projetos de Pesquisa do HCFMUSP-CAAE: 59125316.4.000.0068) and was conducted in accordance with the declaration of Helsinki of 1964 and its later amendments. All participants provided written informed consent. The study was registered at ClinicalTrials.gov (NCT03104062). 
Data Availability. The datasets generated and/or analyzed during the current study are available from the corresponding author on reasonable request.

Open Access. This article is licensed under a Creative Commons Attribution-NonCommercial 4.0 International License, which permits any non-commercial use, sharing, adaptation, distribution and reproduction in any medium or format, as long as you give appropriate credit to the original author(s) and the source, provide a link to the Creative Commons licence, and indicate if changes were made. The images or other third party material in this article are included in the article's Creative Commons licence, unless indicated otherwise in a credit line to the material. If material is not included in the article's Creative Commons licence and your intended use is not permitted by statutory regulation or exceeds the permitted use, you will need to obtain permission directly from the copyright holder. To view a copy of this licence, visit http://creativecommons.org/licenses/by$\mathrm{nc} / 4.0 /$.

\section{REFERENCES}

1. Nicolau JC, Maia LN, Vítola-João VVD, et al. STsegment resolution and late (6-month) left ventricular remodeling after acute myocardial infarction. Am J Cardiol. 2003;91(4):451-3.

2. de Lemos JA, Antman EM, Giugliano RP, et al. STsegment resolution and infarct-related artery patency and flow after thrombolytic therapy. Am J Cardiol. 2000;85(3):299-304.

3. Sabatine MS, López-Sendón JL, Cools F, Braunwald E. Addition of clopidogrel to aspirin and fibrinolytic therapy for myocardial infarction with ST-segment elevation. N Engl J Med. 2005;352:1179-89.

4. Wallentin L, Becker RC, Budaj A, et al. Ticagrelor versus clopidogrel in patients with acute coronary syndromes. N Engl J Med. 2009;361(11):1045-57.

5. Berwanger O, Lopes RD, Moia DDF, et al. Ticagrelor versus clopidogrel in patients with STEMI treated with fibrinolysis: TREAT trial. J Am Coll Cardiol. 2019;73(22):2819-28.
6. Berwanger O, Nicolau JC, Carvalho AC, et al. Ticagrelor versus clopidogrel after fibrinolytic therapy in patients with ST-elevation myocardial infarction: Rationale and design of the ticagrelor in patients with ST elevation myocardial infarction treated with thrombolysis (TREAT) trial. Am Heart J. 2018;202:89-96.

7. Berwanger O, Nicolau JC, Carvalho AC, et al. Ticagrelor vs clopidogrel after fibrinolytic therapy in patients with ST-elevation myocardial infarction: a randomized clinical trial. JAMA Cardiol. 2018;3(5): 391-9.

8. Cattaneo M, Schulz R, Nylander S. Adenosine-mediated effects of ticagrelor: evidence and potential clinical relevance. J Am Coll Cardiol. 2014;63(23): 2503-9.

9. Layland J, Carrick D, Lee M, Oldroyd K, Berry C. Adenosine: physiology, pharmacology, and clinical applications. JACC Cardiovasc Interv. 2014;7(6): 581-91.

10. Multiplate ${ }^{\circledR}$ analyzer [Internet]. https:// diagnostics.roche.com/global/en/products/ instruments/multiplate-6-analyzer. html\#productInfo. Accessed 25 Jul 2019.

11. Caldas MA, Tsutsui JM, Kowatsch I, et al. Value of myocardial contrast echocardiography for predicting left ventricular remodeling and segmental functional recovery after anterior wall acute myocardial infarction. J Am Soc Echocardiogr. 2004;17(9):923-32.

12. Park K, Cho Y-R, Park J-S, Park T-H, Kim M-H, Kim Y-D. Comparison of the effects of ticagrelor and clopidogrel on microvascular dysfunction in patients with acute coronary syndrome using invasive physiologic indices. Circ Cardiovasc Interv. 2019;12(10):e008105.

13. Nicolau JC, Franken M, Lotufo PA, et al. Use of demonstrably effective therapies in the treatment of acute coronary syndromes: comparison between different brazilian regions. Analysis of the Brazilian Registry on Acute Coronary Syndromes (BRACE). Arq Bras Cardiol. 2012;98(4):282-9.

14. Fox KAA, Dabbous OH, Goldberg RJ, et al. Prediction of risk of death and myocardial infarction in the six months after presentation with acute coronary syndrome: prospective multinational observational study (GRACE). BMJ. 2006;333(7578): 1091.

15. Goodman SG, Nicolau JC, Requena G, et al. Longerterm oral antiplatelet use in stable post-myocardial infarction patients: Insights from the long Term rIsk, clinical manaGement and healthcare Resource utilization of stable coronary artery dISease 
(TIGRIS) observational study. Int $\mathrm{J}$ Cardiol. 2017;236:54-60.

16. Gurbel PA, Bliden KP, Butler K, et al. Randomized double-blind assessment of the ONSET and OFFSET of the antiplatelet effects of ticagrelor versus clopidogrel in patients with stable coronary artery disease: the ONSET/OFFSET study. Circulation. 2009;120(25):2577-85.

17. Storey RF, Angiolillo DJ, Patil SB, et al. Inhibitory effects of ticagrelor compared with clopidogrel on platelet function in patients with acute coronary syndromes: the PLATO (PLATelet inhibition and patient Outcomes) PLATELET substudy. J Am Coll Cardiol. 2010;56(18):1456-62.

18. Steg PG, James S, Harrington RA, et al. Ticagrelor versus clopidogrel in patients with ST-elevation acute coronary syndromes intended for reperfusion with primary percutaneous coronary intervention: a platelet inhibition and patient outcomes (PLATO) trial subgroup analysis. Circulation. 2010;122(21): 2131-41.

19. Chapin JC, Hajjar KA. Fibrinolysis and the control of blood coagulation. Blood Rev. 2015;29(1):17-24.

20. Longstaff C, Kolev K. Basic mechanisms and regulation of fibrinolysis. J Thromb Haemost JTH. 2015;13(Suppl 1):S98-105.

21. Diego A, de Prado AP, Cuellas C, et al. P2Y12 platelet reactivity after thrombolytic therapy for STsegment elevation myocardial infarction. Thromb Res. 2012;130(3):e31-36. 